\title{
Exopthalmia in Cross Bred Cattle Naturally Infected with Theileria annulata
}

\author{
Sabhyata Sharma, S. W. Kolte and Swapnil Magar \\ Department of Veterinary Parasitology, Nagpur Veterinary College, \\ MAFSU, Nagpur-440006, India \\ *Corresponding author
}

\section{Keywords}

Theileria annulata, Exopthalmia, Cross bred cattle

\section{Article Info}

Accepted:

07 August 2020 Available Online:

10 September 2020

\section{A B S T R A C T}

Theileriosis is a tick borne haemoprotozoan disease caused by Theileria spp, Theileria annulata and Theileria orientalis most commonly. The disease has gained economic importance as it causes huge losses to farmers in the form of decrease milk production and expensive treatment of the disease. Thin blood smears and blood in EDTA from the ear vein of a Jersey cross bred female cattle aged 5 years was referred to the Department of Parasitology, Nagpur Veterinary College, Nagpur, showing symptoms of unilateral exophthalmia of left eye, severe lacrimal discharge, moderately swollen lymph nodes and increased temperature with no other clinical signs. Thin blood smear was stained with Giemsa's stain and revealed positive for piroplasms of Theileria in smear. The blood was also subjected to PCR using specific primers of Theileria annulata (Tams1) and Theileria orientalis (MPSP).PCR reaction has confirmed Theileria annulataby observing band of $750 \mathrm{bp}$ which encodes the $30 \mathrm{kDa}$ major merozoite surface antigen (Tams1). The animal was treated with Buparvoquone(5\%)@ 1ml/20kg body weight. Broad spectrum antibiotics were given to control secondary bacterial infection with Vitamin B complex to boost the immunity. As expected recovery was observed with disappearance of clinical signs and exophthalmia disappeared on $7^{\text {th }}$ day. Exophthalmia in crossbred calves has been reported by many scientists but this is a unique case of exophthalmia in adult cattle.

\section{Introduction}

Theileriosis is a severe and often fatal haemoprotozo an disease of cattle caused by Theileria annulata and Theileria orientalis, mainly. The transmission occurs when the ticks of Hyalomma genus, mainly attaches to the body of hosts and vomits the sporozoites of Theileria sp. through saliva. In tropical countries, it is a major economical disease which hinders the improved livestock production. The prevalence of theileriosis depends on various factors like climatic conditions, age, breed, tick density, geographical area, management factors, environmental factors that plays an important role in the spread of bovine theileriosis. Theileriosis infection in cattle is mostly characterised by clinical signs like high temperature, lymph node enlargement, reduced rumination, lacrimation, diarrhoea, development of corneal opacity, nasal 
discharge and congested conjunctiva. Exophthalmia is not at all reported in adult cross bred cattle but is very common condition in calf cross bred. A new case was reported in Nagpur district with the clinical manifestation of unilateral exophthalmia with moderately swollen lymph nodes. There are no scientific reports demonstrating adult cross bred cattle with theileriosis bestowing clinical manifestation of exophthalmia to the best of the author's knowledge in published electronic data.

The present report demonstrates theileriosis in adult cattle bestowing clinical manifestation of unilateral exophthalmia. Conventional techniques for diagnosis of theileriosis were performed followed by PCR for confirmatory diagnosis, as it is reliable, sensitive technique for diagnosis and also helps to differentiate different species of Theileria.

\section{Materials and Methods}

Thin blood smears and blood in EDTA from the ear vein of a Jersey cross bred female cattle aged 5 years was referred to the Department of Parasitology, Nagpur Veterinary College, Nagpur, with the clinical signs of unilateral exophthalmia of left eye (Fig. 1), severe lacrimal discharge, moderately swollen lymph nodes and increased temperature with no other symptoms. The blood smears were first poured with methanol and then stained with
Giemsa's stain, and examined for haemoprotozoan under compound microscope.

The blood sample in EDTA was subjected to PCR for confirmation of the species. DNA isolation was done using Favorgen kit, as per the manufacturers instructions. Two PCR reactions using primers of Theileria annulata (Tams1) and Theileria orientalis (MPSP) were carried out.

\section{Results and Discussion}

\section{Blood smear examination}

Thin blood smear examination using Giemsa's stain revealed the presence of piroplasms in erythrocytes (Fig. 2) under compound microscope (100X).

\section{PCR Diagnosis}

In the present study, PCR protocol was standardised for the diagnosis of Theileria annulata and Theileria orientalis in cattle. The PCR assay was conducted using species specific primers for Theileria annulata and Theileria orientalis targeting Tams1 and MPSP gene, respectively. The PCR reaction was amplified using respective primers and amplification was carried out at 750bp which encodes the $30 \mathrm{kDa}$ major merozoite surface antigen (Fig. 3).

Fig.1 Exopthalmia with severe lacrimation in cattle

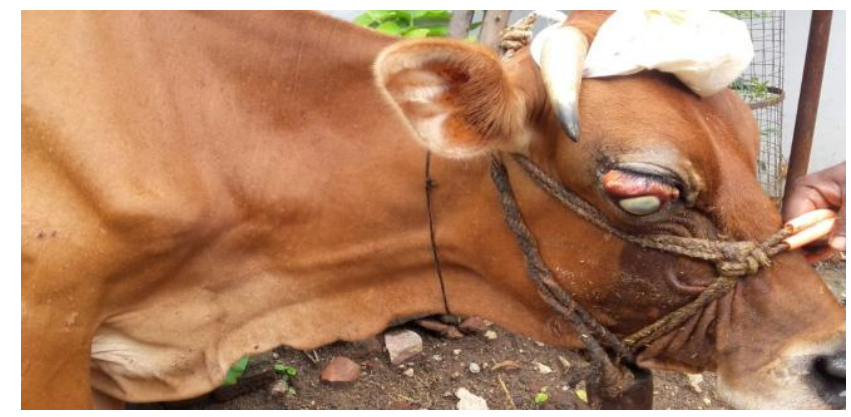


Fig.2 Piroplasms of Theileria in erythrocytes

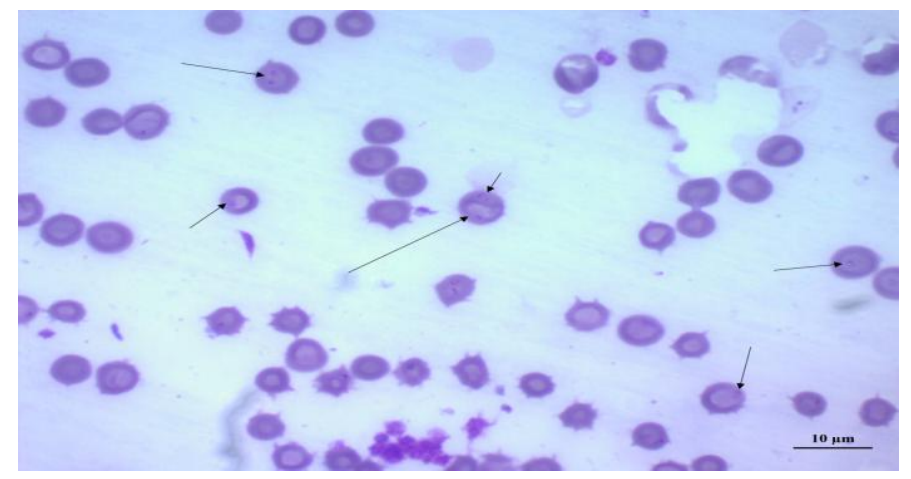

Fig.3 Agarose gel electrophoresis of amplified Theileria annulata DNA

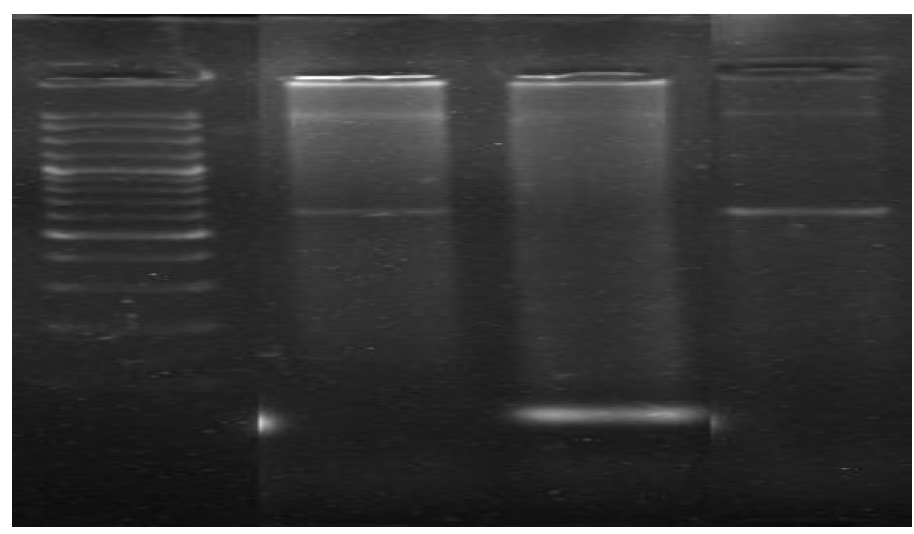

Fig.4 Recovery seen after treatment with Buparvoquone

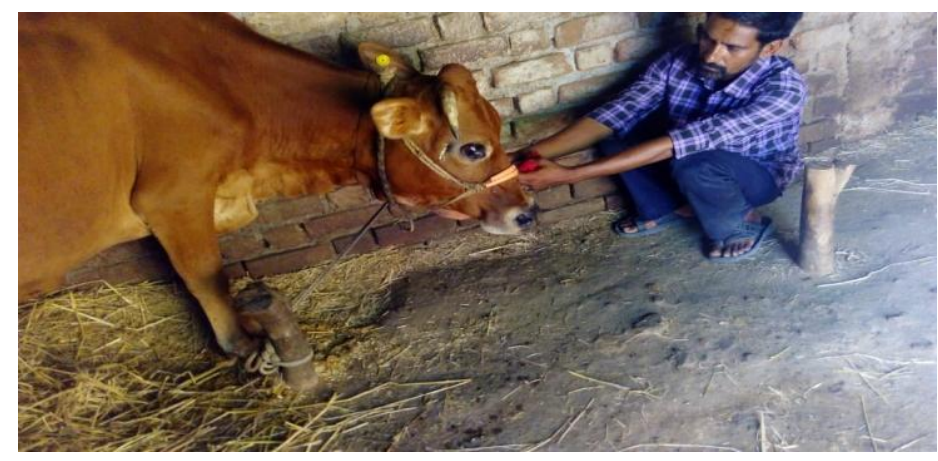

\section{Treatment}

The animal was treated with Buparvoquone $(5 \%) @ 1 \mathrm{ml} / 20 \mathrm{~kg}$ body weight. Broad spectrum antibiotics were given to control secondary bacterial infection with Vitamin B complex to boost the immunity. Uneventful recovery was observed after $24 \mathrm{hrs}$, the animal become normal, the exophthalmia reduced after $48 \mathrm{hrs}$ and complete recovery of the eye was observed on $7^{\text {th }}$ day. Exopthalmia in crossbred calves has been reported (Sudan et al., 2012). This is the first case in adult crossbred cattle hence the author thought to put it on record (Fig. 4). 
According to the clinical signs observed, it is found that buldging of eye ball is mostly recorded in calves (Sudan et al, 2012) which is a heritable trait, mostly found at the age of 6months. The affected animal has defective vision and display difficulty in walking in unfamiliar surroundings (Smith 1990). Exopthalmia could be a consequence of slow developing ophthalmic neoplasm (lymphosarcoma) characterized by reduced ocular mobility, corneal ulcerations and exposure keratitis. It has also been reported as an outcome of retrobulbar abscesses or post orbital cysts/granuloma and sweet clover poisoning, etc. (Aiello and Mays 1998) characterized by loss of vision, intraocular bleeding and corneal oedema. As exopthalmia is reported in cross bred calves at several areas. But this is the first time, it has been reported in adult cattle. So the author thought to put it in the record.

\section{References}

Aiello SE, Mays A (1998) The Merck veterinary manual, 8th edn. Merck and Co Inc., New Jursey, pp 31-33, 273 283, 463-464.

Bhatia BB, Shah HL. Protozoa and protozoan diseases of domestic animals. India: ICAR Publication; 2001. pp. 148-158.

Demessie, Y., and Derso, S. (2015). Tick borne hemoparasitic diseases of ruminants: A review. Advances in Biological Research, 9(4), 210-224.

Devendra, C. (1995): In Global Agenda for Livestock Research, EDS, ILRI, Nairobi., pp. 4148.

Godara R, Sharma RL, Sharma CS. Bovine tropical theileriosis in a neonate calf. Trop Anim Health Prod. 2009; 42(4): 551-553. doi: 10.1007/s11250009-9469-6.

Ingle, P. P. N. (2017) Pathology and diagnosis of Theileria annulata and Theileria orientalisin buffaloes. Submitted to
Maharashtra Animal and Fisheries Sciences and University, Nagpur.

Kakati, P., Sarmah, P. C., Ray, D., Bhattacharjee, K., Sharma, R. K., Barkalita, L. M., and Stanley, B. (2015). Emergence of oriental theileriosis in cattle and its transmission through Rhipicephalus (Boophilus) microplus in Assam, India. Veterinary world, 8(9), 1099.

Khatoon, S., Kolte, S. W., Kurkure, N. V., Chopde, N. A., and Jahan, A. (2015). Detection of tropical bovine theileriosis by polymerase chain reaction in cattle.Journal of parasitic diseases, 39(1), 53-56.

Kolte, S. W., Larcombe, S. D., Jadhao, S. G., Magar, S. P., Warthi, G., Kurkure, N. V., and Shiels, B. R. (2017). PCR diagnosis of tick-borne pathogens in Maharashtra state, India indicates fitness cost associated with carrier infections is greater for crossbreed than native cattle breeds. PloS one, 12(3), e0174595.

Minjauw B, McLeod A (2003) Tick-borne diseases and poverty. The impact of ticks and tick-borne diseases on the livelihood and marginal livestock owners in India and Eastern and Southern Africa. Research Report, DFID Animal Health Programme, Centre of Tropical Veterinary Medicine, University of Edinburgh.

Radostits OM, Blood DC, Gay CC. Veterinary medicine - a textbook of diseases of cattle, sheep, pigs, goats and horses. $8 . \quad$ London: BailliereTindall; 1994. pp. 1206-1212.

Randhawa SS, Nauniyal DC, Singh KB. Atypical ocular lesions in theileriosis in crossbred Indian calves. J Vet Med. 1983; 3: 99-100.

Smith BP. Large animal internal medicinediseases of horse, cattle, sheep and goat. St. Louis: C. V. Molsby 
Publications; 1990. pp. 978-1205.

Sengupta PP, Bansal GC, Ray D. Ocular lesions in experimental theileriosis. $\mathbf{J}$ Vet Parasitol. 1993; 7(2):127-129.

Soulsby EJL. Helminths, arthropods and protozoa of domesticated animals, ELBS-7. London: Bailliere Tindal; 2005. pp. 728-737.

Sudhan NA, Sinha BP, Verma SP. Ocular involvement of calves in $T$. annulata infection lesion. $\mathrm{J} \quad$ Vet Med. 1987; 7: 133-134.

Sudan V, Sharma RL, Borah MK, Mishra R.
Acute bilateral proptosis in a cross bred calf naturally infected with Theileria annulata. J Parasit Dis. 2012; 36(2): 215-219. doi: 10.1007/s12639-0120111-6.

Sudan V, Sharma RL, Yadav R, Borah MK. Turning sickness in a cross bred cow naturally infected with Theileria annulata. J Parasit Dis. 2012; 36(2): 226-229. doi: 10.1007/s12639-0120113-4.

\section{How to cite this article:}

Sabhyata Sharma, S. W. Kolte and Swapnil Magar. 2020. Exopthalmia in Cross Bred Cattle Naturally Infected with Theileria annulata. Int.J.Curr.Microbiol.App.Sci. 9(09): 493-497. doi: https://doi.org/10.20546/ijcmas.2020.909.062 